\title{
Photovoltaic Module Performance and DurabilityECEIUED Following Long-Term Field Exposure
}

\author{
D. L. King, M. A. Quintana, J. A. Kratochvil, \\ D. E. Ellibee, and B. R. Hansen \\ Sandia National Laboratories \\ Albuquerque, NM 87185-0752 \\ www.sandia.gov/pv/
}

\begin{abstract}
Our investigations of both new and field-aged photovoltaic modules have indicated that, in general, today's commercially available modules are a highly reliable product. However, by using new test procedures, subtle failure mechanisms have also been identified that must be addressed in order to achieve 30-year module lifetimes. This paper summarizes diagnostic test procedures, results, and implications of in-depth investigations of the performance and durability characteristics of commercial modules after long-term field exposure. A collaborative effort with U.S. module manufacturers aimed at achieving 30-year module lifetimes is also described.
\end{abstract}

\section{INTRODUCTION}

For many years, one of the long-term goals of the U.S. Department of Energy's Photovoltaic Program has been to promote the development of cost-effective photovoltaic modules with 30 -year useful lifetimes $(1,2)$. Module manufacturers have worked diligently toward this goal, as have researchers in the national laboratories. Accelerated aging tests and qualification test procedures have been used to anticipate failure mechanisms, and to establish quality standards for marketing purposes. Significant progress has been made, but additional research is still required and manufacturers will have to establish rigorous quality control standards in order to achieve the long-term goal.

As a result of the relatively slow evolution of photovoltaic technology, an additional opportunity now exists for more rapidly improving the lifetime of modules. A large number of "qualified" modules, from established manufacturing facilities, have now been in the field for many years, in some cases almost twenty. Detailed investigation of these field-aged modules has resulted in new techniques for identifying degradation mechanisms and has provided additional insight required in optimizing manufacturing processes for extended module lifetime. This paper summarizes test procedures and results obtained during collaborative investigations of durability issues resulting from extended field exposure.

Sandia is a multi-program laboratory operated by Sandia Corporation, a Lockheed Martin Company, for the U.S. Department of Energy under contract DE-AC04-94AL8500. 


\section{MODULE DURABILITY ANALYSES}

Until recently, relatively little effort had been made to evaluate the degradation mechanisms in field-aged modules, partially because of the difficulty in dissecting the laminated modules and partially because of the lack of established diagnostic procedures. Progress has been made in both areas. The following sections of this paper briefly describe both destructive and non-destructive procedures that have been applied to field-aged modules, along with illustrative examples.

\section{Superstrate Materials}

The superstrate used for the front surface of flat-plate photovoltaic modules has typically been tempered, low-iron, rolled, sheet glass that is about 3.2-mm thick. AFG Industries or PPG have typically manufactured most of the sheet glass used for modules manufactured in the U.S. This cover glass serves several purposes in the module: mechanical rigidity, impact resistance, optical transparency, electrical isolation of the solar cell circuit, and outdoor weatherability. Manufacturers of new thin-film photovoltaic modules have typically chosen to use non-tempered low-iron glass, or polymers such as DuPont Tefzel ${ }^{\mathrm{TM}}$, as the module superstrate material. The mechanical strength and impact resistance of commercial modules are verified through standardized qualification tests that employ thermal cycling, mechanical loading and twisting, and ice-ball (hail) impact tests (3). Through our investigation of field degradation mechanisms, additional characteristics of the superstrate materials, beyond those evaluated during qualification tests, have been determined.

\section{Spectral Transmittance}

Module superstrate materials should have a high spectral transmittance for all wavelengths of sunlight to which photovoltaic cells in the module respond. However, one important tradeoff has to do with the transmittance of short-wavelength ultraviolet (UV) sunlight. Typically, the polymer encapsulants used to laminate the superstrate to the solar cells in a module are degraded by extended exposure to UV light. Therefore, it is desirable for the module superstrate to prevent ultraviolet sunlight $(<400 \mathrm{~nm})$ from reaching the encapsulant material. Although low-iron glass formulations have varied somewhat over the years, the glass industry has arrived at formulations that appear to be a good tradeoff between encapsulant protection and loss of usable light to the solar cells. To screen out UV light, a small amount of the element cerium (Ce) was added to glass formulations used for photovoltaic modules, starting in about 1990. Another desirable optical characteristic for the superstrate would be rejection of infrared (IR) sunlight of wavelengths longer than usable by the solar cells. The rejection of the infrared sunlight would raise module performance and increase module lifetime by reducing operating temperatures. However, a cost-effective method for rejecting the infrared heat has not been developed. 


\section{DISCLAIMER}

This report was prepared as an account of work sponsored by an agency of the United States Government. Neither the United States Government nor any agency thereof, nor any of their employees, make any warranty, express or implied, or assumes any legal liability or responsibility for the accuracy, completeness, or usefulness of any information, apparatus, product, or process disclosed, or represents that its use would not infringe privately owned rights. Reference herein to any specific commercial product, process, or service by trade name, trademark, manufacturer, or otherwise does not necessarily constitute or imply its endorsement, recommendation, or favoring by the United States Government or any agency thereof. The views and opinions of authors expressed herein do not necessarily state or reflect those of the United States Government or any agency thereof. 


\section{DISCLAIMER}

Portions of this document may be illegible electronic image products. Images are produced from the best available original document. 
Figure 1 illustrates our spectral transmittance measurements for the low-iron glass typically used for photovoltaic modules, and for the Tefzel ${ }^{\mathrm{TM}}$ polymer now also used for some modules. When these materials are bonded to solar cells with typical encapsulants, the effective transmittance is about $96 \%$, with the primary optical loss of about $4 \%$ being reflectance from the front surface of the material. The 1989-vintage tempered glass sample was extracted from a module exposed in the field for about 6 years. These transmittance measurements suggested that current-vintage glass without the $\mathrm{Ce}$ additive would be worse than the glass formulations used in 1989, from an encapsulant protection perspective. Similarly, the Tefzel ${ }^{\mathrm{TM}}$ material has very high UV transmittance, providing minimal UV protection for the encapsulant. As is illustrated later, current vintage glass with the $\mathrm{Ce}$ additive has demonstrated a significant improvement in encapsulant protection. A convenient way for detecting the presence of Ce in glass samples is to illuminate them with a common 375-nm "black light." If $\mathrm{Ce}$ is present in the sample, it will fluoresce a distinctive magenta color.

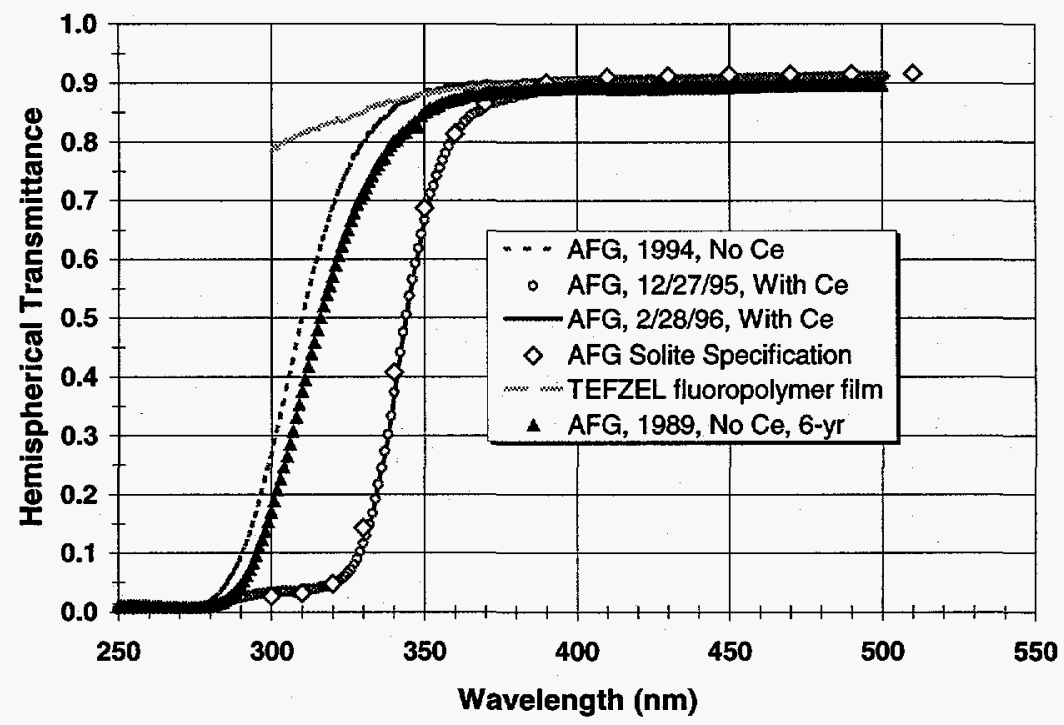

FIGURE 1. Spectral hemispherical transmittance of module superstrate materials including recent vintage $\mathrm{AFG}$ Solite ${ }^{\mathrm{TM}}$ glass samples with and without Ce additive, field-aged 1989-vintage AFG glass sample, and DuPont Tefzel ${ }^{\mathrm{TM}}$ polymer sample.

\section{Impact Resistance}

Another tradeoff exists regarding the degree of impact resistance provided by the superstrate material, cost being the competing factor. Historically, an adequate level of impact resistance has been defined by standardized qualification tests as the ability to withstand impact testing using $2.54-\mathrm{cm}$ diameter ( 8 gram) ice balls propelled at $23 \mathrm{~m} / \mathrm{s}$. Many years of field experience with typical ground-mounted arrays of modules have indicated that this criterion is a reasonable compromise. However, recent analysis of module breakage in a roof-mounted array identified another impact-induced failure mode that must be addressed by system designers. Field investigation, followed by 
fracture analysis, and then impact testing in the lab confirmed that small (2 to 4 gram) stones propelled in storms to relatively low velocities $(10$ to $15 \mathrm{~m} / \mathrm{s})$ are capable of fracturing the tempered glass superstrates used on most photovoltaic modules. The significance of this finding for designers of roof-mounted systems is that stones (gravel) of this size are commonly used as the top covering on commercial and residential roofs.

Figure 2 illustrates glass cross-sections used during fracture analysis of field samples to diagnose the cause of failure. When glass breaks, it effectively "freezes" the stressstrain characteristics present in the glass at the instant of fracture. To glass-fracture analysts, a recorded image of the glass failure process is provided by visible features in the glass cross-section. A few of the terms used to describe these features are hackle, mist, and Wallner lines. For the storm-induced glass failures we investigated, fracture analysis provided convincing evidence that breakage was not due to mechanical wind loading or substandard module materials. Instead, the breakage was due to wind-blown roofing gravel sliding up the face of modules, launching from the top, and then impacting the next row of modules at near-normal angles of incidence. Wind speeds during the storm were estimated to be less than $25 \mathrm{~m} / \mathrm{s}$.
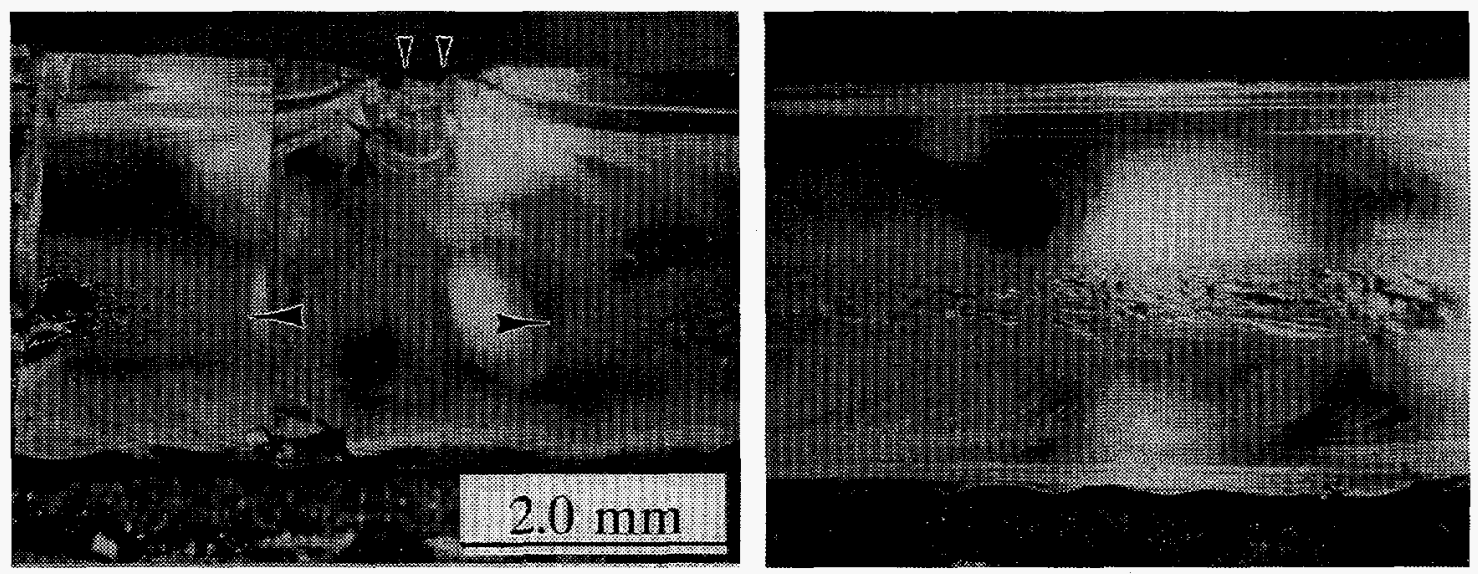

FIGURE 2. Cross-sections of tempered glass sample used by glass fracture analysts to diagnose cause of failure in module fractured by wind-blown roofing gravel.

\section{Extracting Tempered Glass Samples}

In order to investigate the properties of the tempered glass superstrates from fieldaged modules, it was necessary to develop a technique for removing samples of a size compatible with test equipment. Most people familiar with tempered glass will tell you that it is not possible to remove selected samples from tempered glass, let alone control the size of the sample. Typically, when tempered glass breaks, the entire sheet of glass fractures ("dices") into small fragments. This characteristic of tempered glass makes it impossible to use conventional coring tools to remove glass samples. However, by modifying procedures developed for security-related programs at Sandia, a new technique was demonstrated for removing 6-cm diameter samples from tempered glass sheet. These samples were then used for analytical measurements, like the spectral 
transmittance data previously shown in Figure 1. Basically, the new procedure involved bonding a preheated aluminum ring to the tempered glass. After the aluminum ring cooled, the glass sample within the ring was left under a high level of compressive stress. The high degree of compressive stress made it possible to break away the glass external to the aluminum ring, leaving an intact sample of glass. Figure 3 shows typical samples still bonded to the aluminum rings.

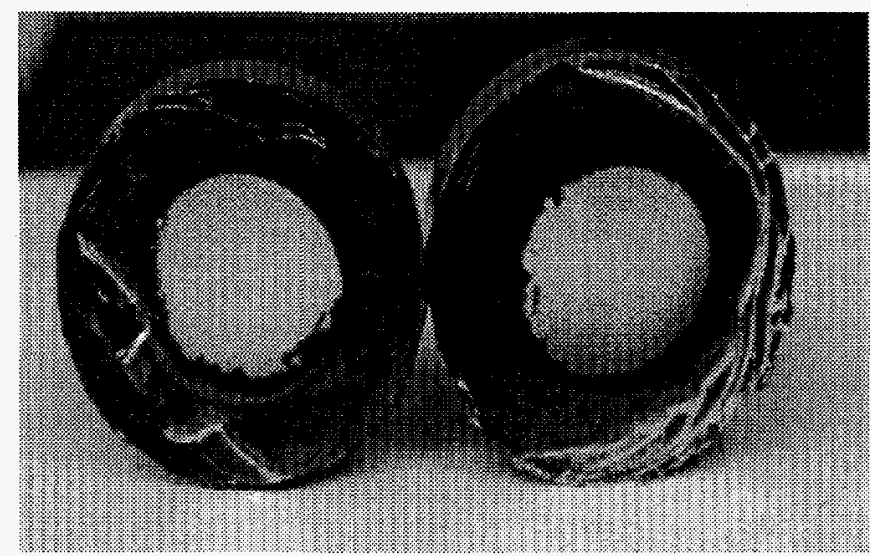

FIGURE 3. Glass samples removed from a sheet of 3.2-mm thick tempered glass using new procedure. Glass samples are still bonded to the $6-\mathrm{cm}$ diameter aluminum rings used during the extraction process.

\section{Encapsulant}

As does the module superstrate material, the module encapsulant must serve several purposes. The encapsulant's primary purpose is to bond, or laminate, the multiple layers of a module together. Additional encapsulant characteristics must include high optical transmittance, good adhesion to different module materials, adequate mechanical compliance to accommodate stresses induced by differences in thermal expansion coefficients between glass and cells, and good dielectric properties (electrical insulation). Over the years, a variety of encapsulant materials has been used in modules including: polyvinyl butyral (PVB), silicone rubber, ethylene-vinyl-acetate (EVA), and more recently, other proprietary encapsulants.

\section{Optical Losses in Encapsulant}

For almost 15 years, the dominant encapsulant material in the industry has been EVA. As a result, a significant level of research has been aimed at understanding and improving the properties of EVA for application in photovoltaic modules $(4,5,6)$. Particular emphasis has been given to minimizing the propensity of EVA to "brown" after long-term exposure to UV sunlight with module operating temperatures near 50 ${ }^{\circ} \mathrm{C}$. Figure 4 shows the typical effect of "browning" on the spectral transmittance of "standard cure" EVA (A9918) samples extracted from field-aged modules of about 
1985-vintage. These modules used low-iron glass superstrates manufactured prior to the addition of the Ce additive to screen out UV sunlight.

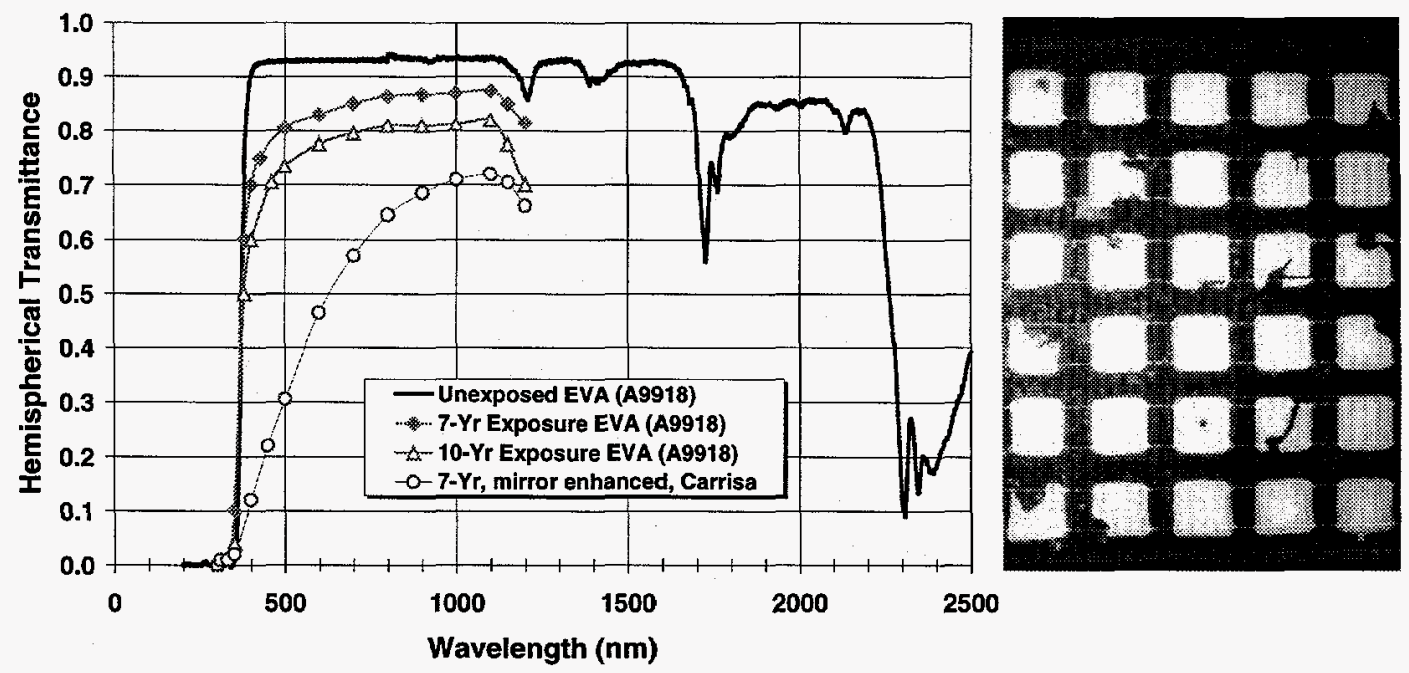

FIGURE 4. (Left) Spectral hemispherical transmittance of EVA encapsulant samples removed from 1985-vintage modules after 7 and 10-year exposure. Third sample was from a module with 7 -yr mirror enhanced exposure, Carrisa Plains system. (Right) Photo of EVA browning patterns after 10-yr exposure obtained by illuminating module with ultraviolet $(375 \mathrm{~nm})$ light.

Research has now led to improved understanding of the EVA polymer and to new formulations that are more UV tolerant $(5,6)$. When used with the Ce-doped glass superstrates, the performance loss associated with "browning" in current formulations of EVA is not considered to be a significant problem by the module industry. Long-term outdoor exposure testing at Sandia has demonstrated the effectiveness of Ce-doped glass in combination with "fast-cure" EVA (15295) in minimizing module performance loss due to encapsulant browning. Figure 5 shows measurements of the short-circuit current $\left(\mathrm{I}_{\mathrm{sc}}\right)$ from a 36-cell multi-crystalline silicon module manufactured with AFG Ce-doped glass and fast-cure EVA. These measurements were recorded during 7 years of continuous outdoor exposure in Albuquerque, New Mexico. Within our measurement repeatability of $\pm 1.5 \%$, no detectable loss in $\mathrm{I}_{\mathrm{sc}}$ has been observed to date.

A convenient way to visually detect the presence of EVA browning is to illuminate the module with a common 375-nm "black light." Regions of EVA that have started to degrade will fluoresce over a broad range of wavelengths, producing a nearly white color (7). In this manner, the onset of encapsulant degradation can be detected before it is visually evident and long before it impacts module performance.

\section{Module Delamination}

Module delamination, resulting from loss of adhesion between the encapsulant on other module layers, is also a failure mechanism that needs to be addressed in order for manufacturers to achieve 30-year product lifetimes. From an industry-wide perspective, 


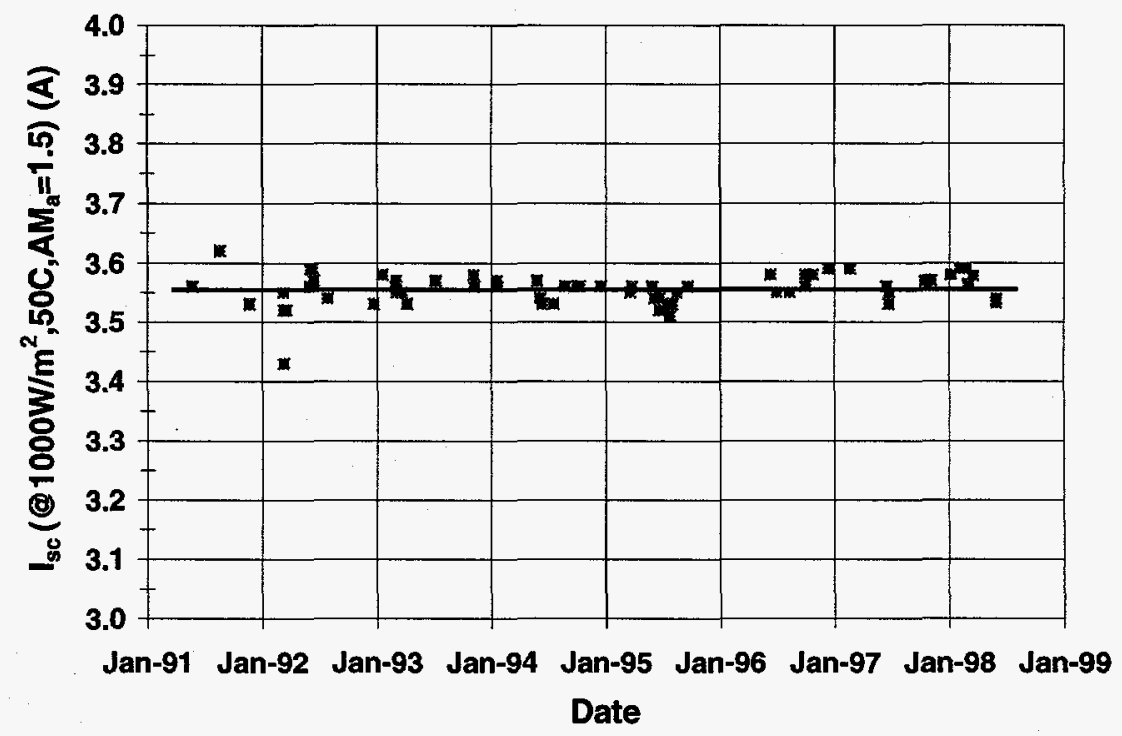

FIGURE 5. Optical durability of the combination of a Ce-doped AFG glass superstrate and fast-cure EVA (15295) encapsulant is demonstrated by negligible loss in module short-circuit current over 7 years of continuous outdoor exposure in Albuquerque, NM.

delamination has occurred in a small percentage of modules manufactured since the mid-1980's. However, it has occurred to varying degrees in modules from all manufacturers, and, because the causes for the failure mechanism are not well understood, it is a continual quality control issue for manufacturers. Most of the delamination observed in the field has occurred at the interface between the encapsulant and the front surface of the solar cells in the module. A common observation has been that delamination is more frequent and more severe in hot and humid climates, sometimes occurring after less than 5 years of exposure. Delamination first causes a performance loss due to optical de-coupling of the encapsulant from the cells. Of greater concern from a module lifetime perspective is the likelihood that the void resulting from the delamination will provide a preferential location for moisture accumulation, greatly increasing the possibility of corrosion failures in metallic contacts. Unfortunately, typical accelerated-aging tests have not been effective in accelerating the mechanisms responsible for delamination, making laboratory investigation of the phenomenon more difficult.

In collaboration with module manufacturers, encapsulant manufacturers, and the Florida Solar Energy Center (FSEC), we have developed and applied new diagnostic techniques that have helped clarify the roles of multiple factors contributing to loss of encapsulant adhesion. Although destructive in nature, the new diagnostic procedures provide the only means available for quantifying encapsulant adhesive strength in fieldaged modules, and for analyzing the chemical influences contributing to delamination. Figure 6 illustrates the mechanical aspects of the diagnostic procedure. Field-aged 
modules were selected for evaluation and mounted on a milling machine. Encapsulant material was removed from the back side of the cell. A diamond-grit coring tool was used to core through the cell material from the back, until contact was made with the module's glass superstrate. A metal screw was bonded to the circular core sample using epoxy. Then, the screw was twisted using a torque measuring tool and the peak torque at adhesive failure was recorded. The peak torque value was used to calculate the peak shear stress when adhesive-failure occurred. Hundreds of samples have been removed in this manner, and for the module types evaluated, virtually every adhesive-failure occurred at the cell-to-encapsulant interface, rather than at the encapsulant-to-glass interface (8). Typical measurements for unexposed silicon modules resulted in peak shear stress at adhesive-failure in the range of 3 to $6 \mathrm{MPa}$ for EVA encapsulant and greater than $15 \mathrm{MPa}$ for non-EVA encapsulants. With field exposure, this adhesive (shear) strength drops, reaching a value of zero when delamination occurs.
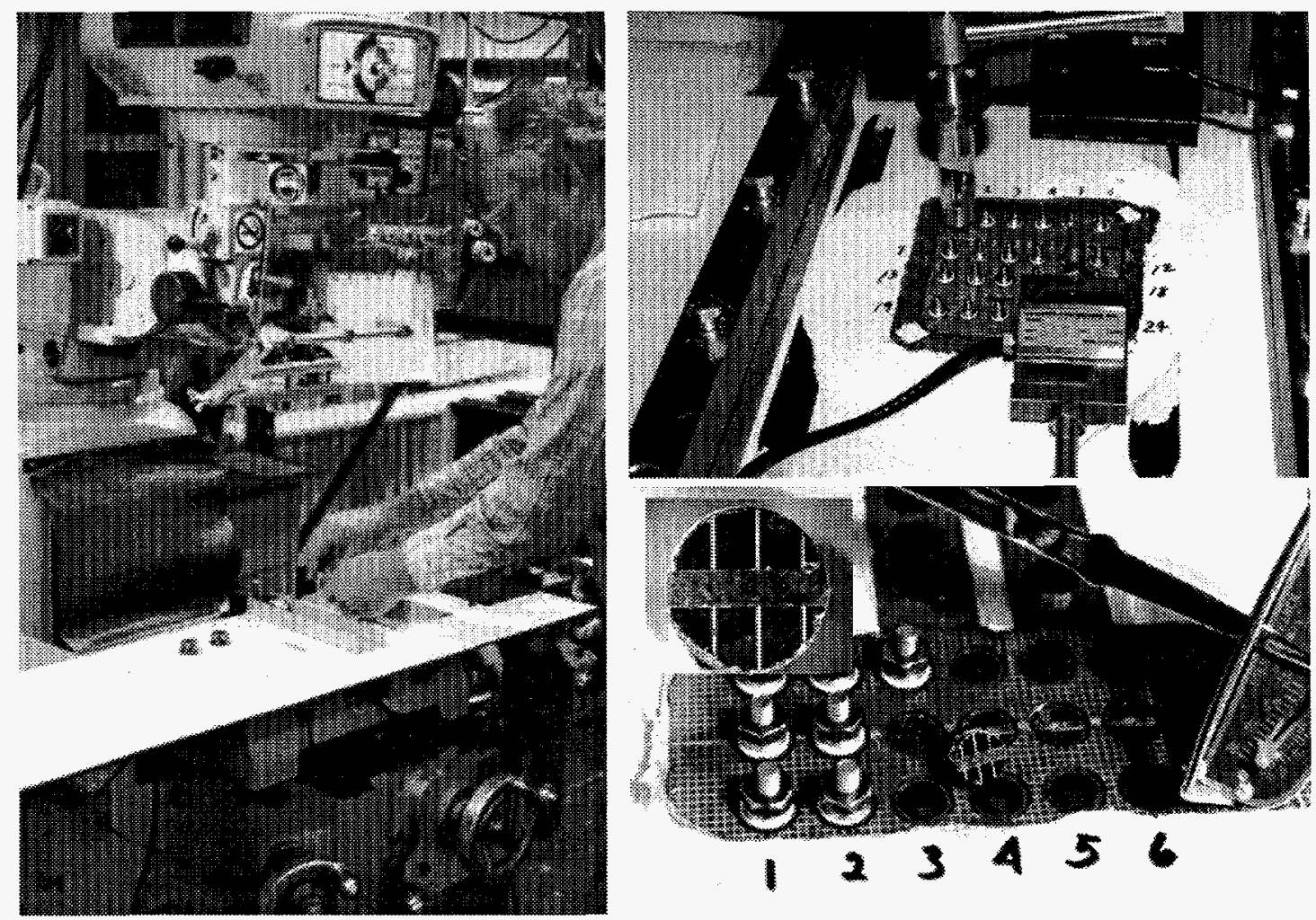

FIGURE 6. A mechanical coring procedure was used to isolate test samples for encapsulant adhesion measurements, chemical analysis of material interfaces, and solder bond evaluation.

Chemical analyses of dozens of cell and encapsulant samples from field-aged modules have also been conducted by FSEC $(9,10)$. The same coring process used to measure encapsulant adhesion was also used to extract cell and encapsulant samples for the chemical analyses. The primary analytical method used for the surface chemical analysis was Auger electron spectroscopy (AES). By comparing samples from unexposed modules to those from field-aged modules, these chemical analyses provided strong evidence of the dynamic chemical activities occurring in the module during field 
exposure. From these analyses, it was clear that sunlight, temperature, and moisture migration through the encapsulant provided the components required for a variety of chemical reactions, many of which may degrade the integrity of the encapsulant's adhesive bond to the cell. Phosphorous, titanium, oxygen, solder flux, encapsulant additives, and even sodium that has migrated through the encapsulant from the glass, are typical reactive materials found at the cell/encapsulant interface after extended field exposure. Additional research will be required to find the combination of materials and manufacturing processes that effectively minimize the loss in encapsulant adhesion with field exposure.

\section{Encapsulant Elasticity}

The mechanical properties of EVA encapsulant have also been suspected of changing as the material ages in the field. Extraction of EVA samples from modules with different levels of field exposure had qualitatively indicated that the older and more brown a sample was, the less elastic it was. In an attempt to quantify this subjective observation, the tensile moduli of an unexposed sample and a standard-cure EVA sample from a module with 7 years of aging on a tropical island were measured using a Rheometrics RSA II machine. Elasticity measurements were made as a function of temperature, from -50 to $100^{\circ} \mathrm{C}$, as shown in Figure 7. Somewhat surprisingly, the tensile modulus of elasticity for these two samples was virtually the same, except at high temperatures (> $60^{\circ} \mathrm{C}$ ) where the aged sample was less elastic. Note that the modulus of elasticity varies by almost two orders of magnitude over what might be expected to be the range for module operating temperatures $\left(-20\right.$ to $\left.70^{\circ} \mathrm{C}\right)$.

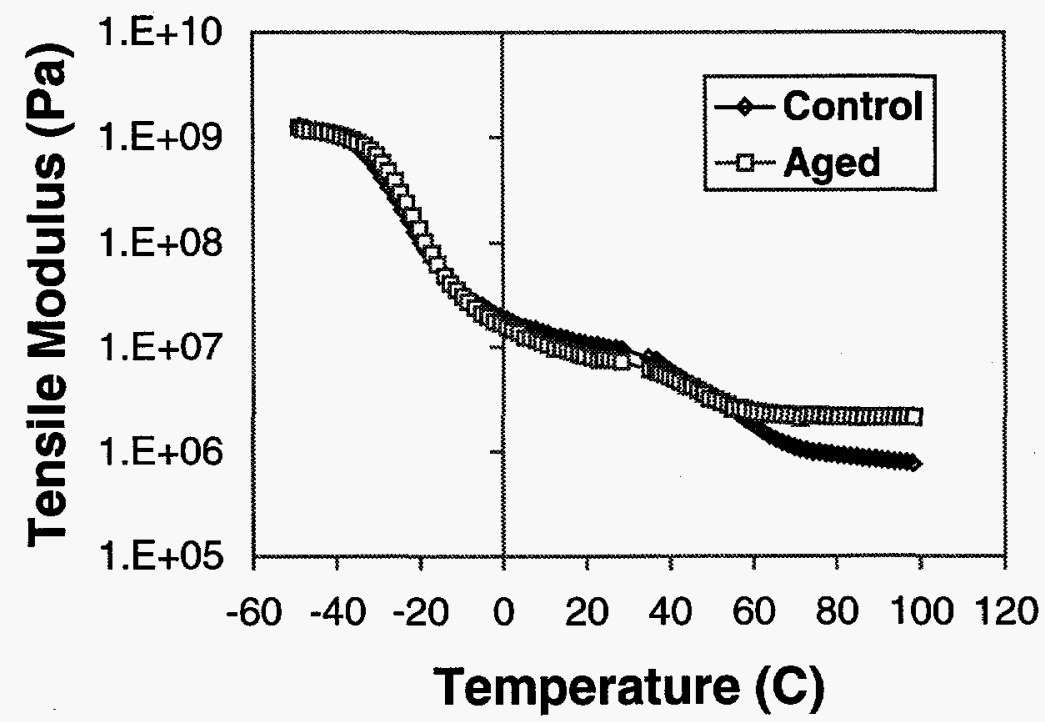

FIGURE 7. Measurements of tensile modulus of elasticity for unexposed standard-cure EVA sample and on a similar sample from a module after 7 years of exposure in the Fiji Islands. 


\section{Series Resistance}

Series resistance present in wiring, junction-box terminations, cell-interconnect ribbons, cell metallization, emitter and base regions of solar cells, and cell solder bonds results in voltage losses, which limit the ultimate performance of a photovoltaic system. As a system ages, gradual increases in the cumulative series resistance results in a decline in power output that may be on the order of $0.5 \% / y r$. Cell designers optimize cell designs to minimize series resistance losses, module manufacturers address resistance in cell metallization and soldered interconnects, and system designers attempt to minimize wiring and termination losses. However, the mechanical influences of daily thermal cycling in the field inevitably result in a gradual increase in series resistance as the system ages. Our work has currently been focused on understanding the effects of field aging on the solder bonds used to interconnect copper ribbons from cell to cell. The same coring procedure previously discussed was used to remove solder bond samples from both unexposed and field-aged modules.

\section{Dark I-V Analysis}

It may be several years before the influence of gradual increases in series resistance losses can be detected from system-level power measurements. However, at the module level, a more direct and sensitive method for quantifying increases in series resistance is the dark current-voltage (I-V) measurement (11). Figure 8 illustrates the effects of adding series resistance during dark I-V measurements on a typical silicon module. This measurement technique is very sensitive to changes in series resistance; changes of $10 \%$ can be readily detected. Dark I-V measurements have been used to analyze the performance of field-aged modules suspected of having series resistance problems. Dark I-V measurements are also very sensitive to changes in shunt resistance and other cell physical properties.

\section{Thermal Infrared Imaging}

Thermal infrared (IR) imaging provided a convenient and non-destructive means for identifying locations in modules where the series resistance was atypically high. The procedure involved connecting a module to a power supply with the module in a forward-biased condition, as in a dark I-V measurement. The power supply was then set to provide continuous current through the module at a level approximately two times the nameplate short-circuit current. As the module heated up, IR images were recorded using a FLIR Systems (Prism DS IR) camera with wavelength sensitivity in the range of 3.6 to 5.0 microns. Using this procedure, solder bonds were identified as a definite source of increased series resistance in some field-aged modules. If the solder bonds were atypically resistive, they showed up as localized hot spots in the IR images. Figure 8 also shows a module with resistive solder bonds after about 6 years in the field. The resistive solder bonds appear as localized hot spots in the $\mathbb{R}$ image. 

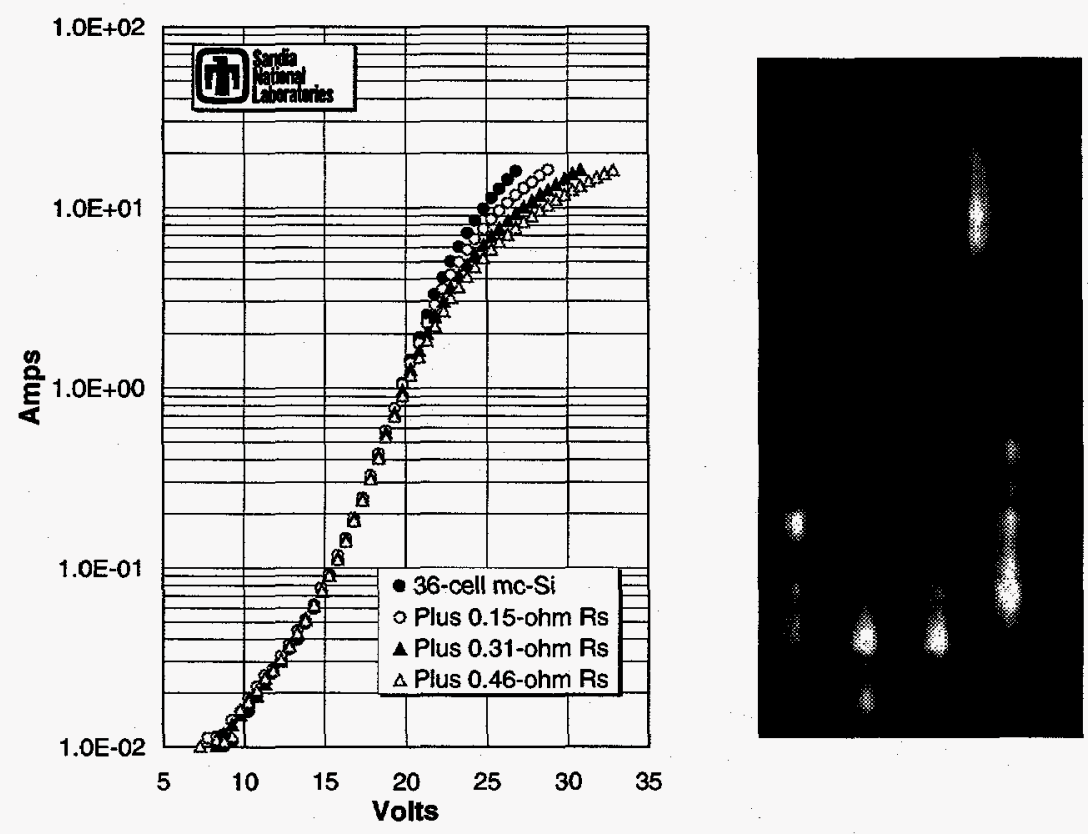

FIGURE 8. (Left) Dark I-V measurements on a typical 36-cell mc-Si module illustrating the influence of adding increased levels of series resistance. (Right) Infrared (IR) image of a silicon module after about six years in the field, showing localized hot spots at atypically resistive solder bond locations. For this image, the module was in forward bias with continuous current flow of about $10 \mathrm{~A}$

\section{Metallurgical Analysis of Solder Bonds}

In order to investigate increased resistance in solder bonds, destructive test procedures were necessary. Using the coring procedure previously discussed, solder bond samples were removed from both unexposed and field-aged modules. These samples were potted in epoxy, mechanically polished, and chemically etched to provide samples for metallurgical analysis. Microscopic investigation of the solder bond crosssections from many modules provided an improved understanding of the influences of both thermal fatigue and manufacturing processes on solder bond integrity.

Figure 9 shows examples of solder bond cross-sections from different module manufacturers. These cross-sections illustrate the variability in cell metallization and solder bond characteristics for typical commercial modules. As solder bonds "age" due to continuous thermal cycling outdoors, expansion and contraction causes the solder to fatigue, become more brittle, and to disassociate into large grains of tin and lead. These phenomena result in a propensity for the solder bonds to crack, becoming more resistive with age. The voids, variations in thickness, and irregular cell metallization shown in Figure 9 increase the likelihood of cracks forming. Effectively, the metallurgical structure of the solder continually changes with time (age) and temperature. All 
modules illustrated have passed current qualification test standards, yet there is still an opportunity to improve the quality of the solder bonds, which will no doubt improve their long-term durability. Work to optimize soldering processes is in progress with individual module manufacturers, again with the goal of achieving 30-year lifetimes.
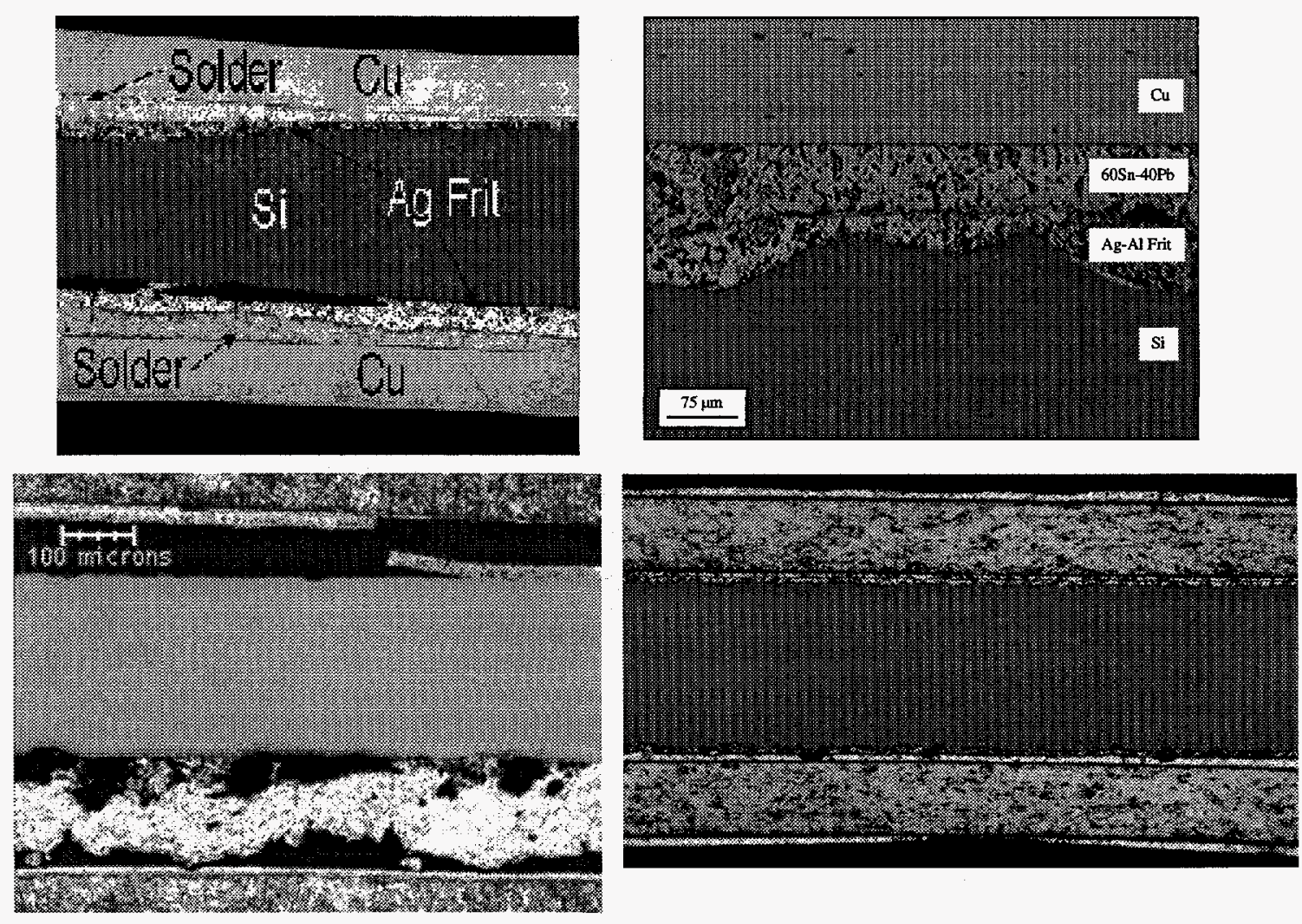

FIGURE 9. Cross-sections of solder bonds in modules from four different manufacturers. From top, layers are copper ribbon, solder, cell metallization, Si cell, cell metallization, solder, and copper ribbon.

\section{0-Year Field Exposure}

The majority of our effort has been applied in the evaluation of field-aged modules that are currently in production. However, valuable module durability information is also available from analysis of modules that have been in the field even longer, even if the original module manufacturer is no longer in business. We recently identified and conducted a field survey of a system with modules from four different manufacturers, all of the modules installed in 1979. These modules will provide durability information after nearly 20 years of real-time exposure for a variety of module designs, superstrates, encapsulants, cell metallizations, and soldering processes. Lessons learned will be documented during this effort, but a primary emphasis will be to identify "success stories." For instance, initial indications are that one of the four manufacturers used cell metallization and soldering processes that have aged very well for 20 years. 
Understanding the characteristics of these manufacturing processes with proven durability, will provide valuable manufacturing insight for today's manufacturers.

\section{Development of New Diagnostic Techniques}

As a result of our analysis of degradation mechanisms, a variety of ideas is being investigated that may lead to new diagnostic techniques that further improve our understanding of module failure mechanisms. Ideally, the improved understanding will then lead to improved accelerated tests for either manufacturing QA or module qualification procedures. Two areas of investigation are embedded moisture sensors and a production-line test, other than "pull strength," for evaluation of solder bond quality.

Moisture migration through module backing materials and through encapsulants is commonly recognized as being involved with the encapsulant browning process and with the chemistry associated with module delamination. However, information is not available that quantifies either the rate or the magnitude of moisture migration in modules. As a result, it is not known whether the moisture migration occurring during accelerated-aging tests corresponds adequately to the migration process that occurs during outdoor exposure. More than likely, it does not. Miniature microelectronic moisture sensors have been developed and are being used to study moisture migration through polymeric materials (12). It should be possible to embed these sensors in modules during the manufacturing process, and subsequently be able to quantify moisture migration inside modules, during either accelerated testing or outdoor environmental conditions.

The integrity of solder bonds has historically been monitored on the production line using a simple mechanical device that measures the force required to peel the soldered interconnect ribbon from a solar cell. A higher "peel" or "pull" strength is typically assumed to indicate a better solder bond. However, this test procedure and this assumption may not be appropriate when the objective is long-term (30-yr) fatigue life. For instance, a solder bond may have a high pull strength, but is mechanically brittle and quickly fails by cracking when exposed to thermal cycles. During the repetitive thermal cycles that a module undergoes outdoors, thermal expansion results in the solder bonds experiencing stresses that are almost entirely in shear, therefore, the typical pull strength measurement is not representative. Because of the large number of thermal cycles to which photovoltaic modules are exposed, thermal fatigue life is a better metric than initial pull strength. However, there is currently no simple test measurement that has been shown to directly correlate with fatigue life. Work in other industries is providing guidance in this area $(13,14)$. 


\section{LONG-TERM EXPOSURE PROGRAM}

Many of the field degradation mechanisms previously discussed, all of which impact the industry's ability to achieve 30-yr module lifetimes, were not identified during the accelerated testing procedures used for product development and qualification testing. As in other industries, there is still a gap between reliability information obtained for accelerated aging tests and that obtained in the real-time application environment. Motivated by an improved understanding of module failure mechanisms, improved testing procedures, and a strong interest from module manufacturers, a collaborative program has been established to expose and closely monitor commercial modules during real-time aging in two distinctly different climates. Sponsored by the U.S. Department of Energy, this cost-shared effort is called the "Module Long-Term Exposure (MLTE)" program. Sandia and the National Renewable Energy Laboratory (NREL) coordinate and provide technical support to the program. The Florida Solar Energy Center (FSEC) in Cocoa, FL, and the Southwest Technology Development Institute (SWTDI) in Las Cruces, NM, provide the exposure sites, routine performance measurements, and monitoring. Module manufacturers provide production samples of modules, manufacturing information, and guidance in interpreting or diagnosing any degradation mechanisms observed.

Current participants in the program include Siemens Solar with both its crystalline silicon (SP-75) module and its copper-indium-diselenide CIGS (ST-10) thin-film module, ASE Americas with its EFG-silicon (ASE-50-AL) module, and United Solar Systems with its triple-junction amorphous silicon (US-60) module. At least three additional module manufacturers are expected to participate, within the next year.

\section{Baseline Performance Characterization}

Experience in evaluating degradation mechanisms in field-aged modules has made the importance of initial baseline testing very clear. It is much easier to detect changes in module characteristics during field exposure if the initial characteristics are accurately known. In support of the MLTE program, Sandia has performed comprehensive baseline testing of over sixty production modules. Baseline tests included visual inspection, dark I-V measurements, infrared imaging, ultrasonic imaging, and outdoor performance calibration relative to traceable world standards.

\section{Module Dark I-V}

As previously discussed, dark I-V measurements are more sensitive to changes in a module's electrical parameters than the more conventional illuminated I-V measurements. The dark I-V measurements are also quick and easy to perform, without the requirement for a calibrated light source. Figure 10 illustrates families of dark I-V measurements obtained on the production samples of modules from two MLTE participants. After outdoor exposure of these modules for a year or more, these 
measurements can be repeated in order to assess changes in electrical performance parameters, such as series and shunt resistance, saturation current, and diode factor.
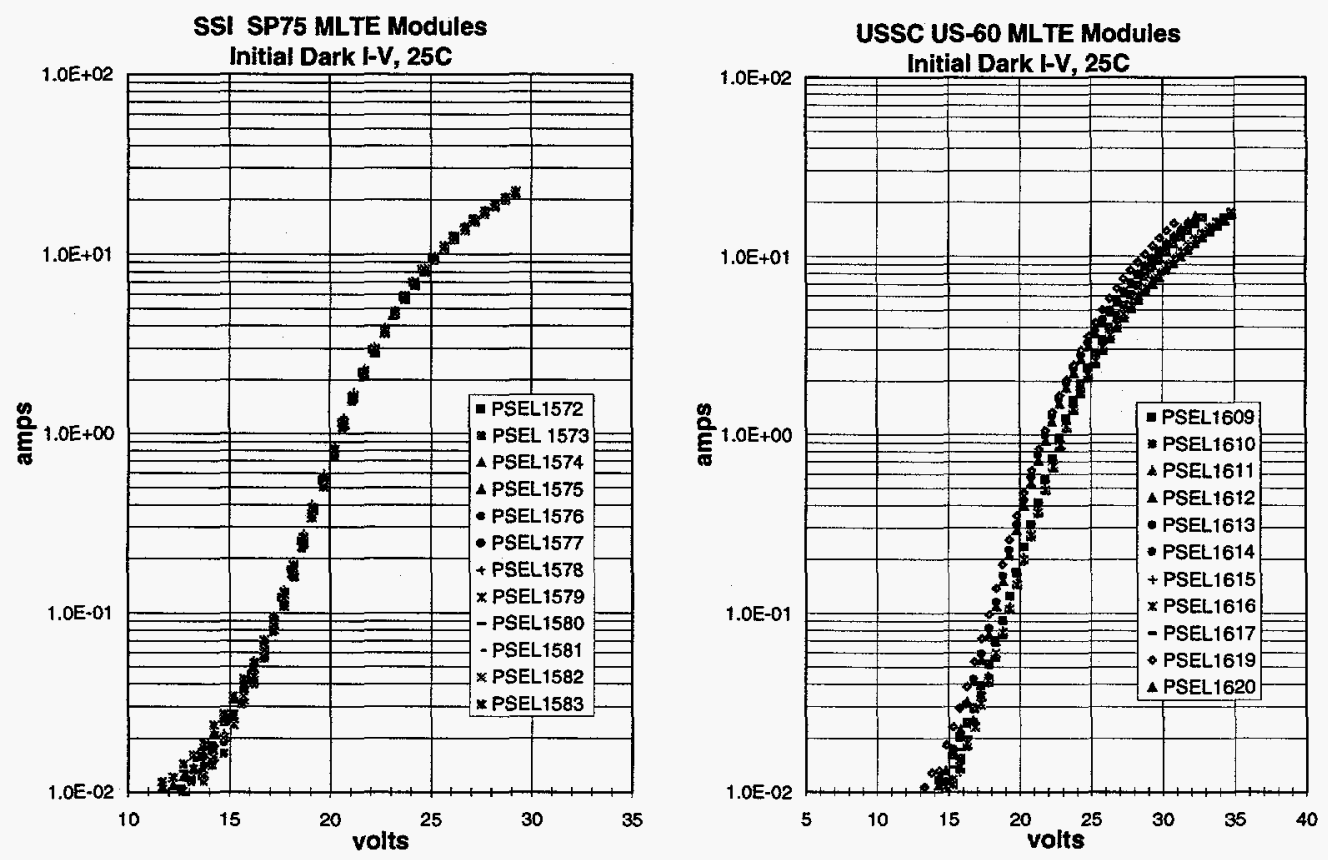

FIGURE 10. Initial dark I-V measurements for production samples of Siemens Solar c-Si (SP-75) modules and United Solar Systems triple-junction a-Si (US-60) modules.

\section{Infrared Imaging}

As previously demonstrated for modules with faulty solder bonds, IR imaging is a useful diagnostic tool for visually characterizing the initial electrical properties of modules. This technique was used as part of the baseline testing for modules in the MLTE program. Subsequent to field exposure, replicate IR images can be used to physically locate where the electrical properties of cells have changed. Resistive solder bonds will show up as localized hot spots, short-circuited cells will look "cold" relative to other cells, etc. By reversing the polarity of the power supply used to provide current to the module, IR imaging can also be used to quickly verify that bypass diodes in the module are correctly wired and functioning. Figure 11 illustrates typical IR images obtained during baseline testing of MLTE modules.

\section{Ultrasonic Imaging}

Ultrasonic imaging is another non-destructive procedure that can be used to evaluate the internal characteristics of laminated modules. It is particularly useful in locating air pockets, or voids, internal to the module that are not visible otherwise (15). Figure 12 shows a typical ultrasonic image obtained by scanning a module using a frequency of 20 $\mathrm{MHz}$. The dark regions in the image indicate air voids internal to the module. 

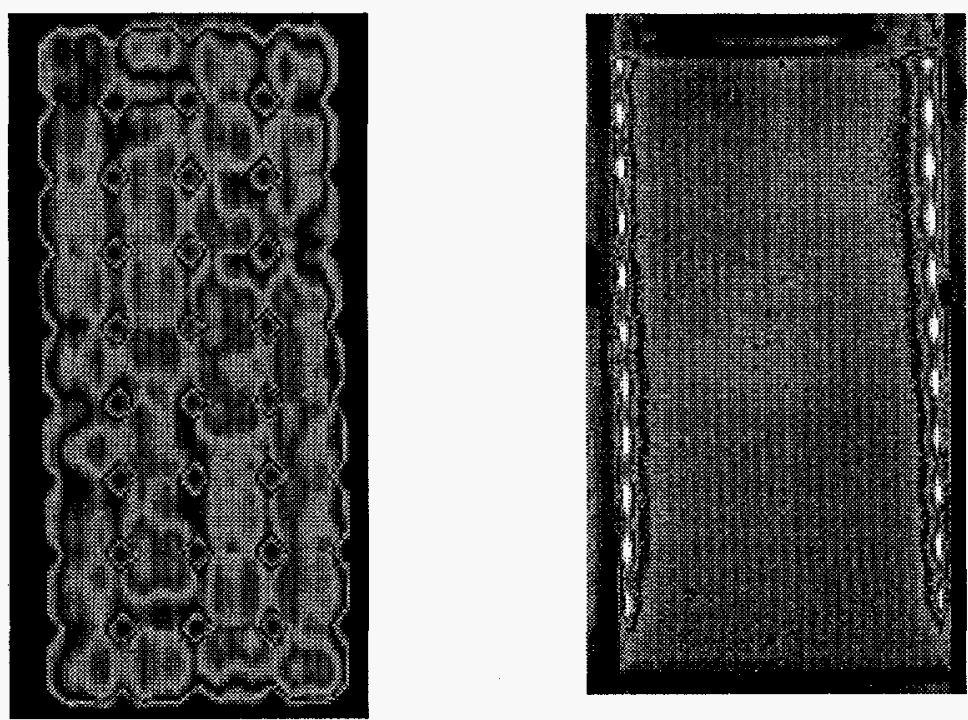

FIGURE 11. Infrared images of crystalline silicon module in forward bias indicating normal temperature distribution with cell variation less than $5^{\circ} \mathrm{C}$ (left) and amorphous silicon module in reverse bias showing correct function of bypass diodes located under module frame (right).

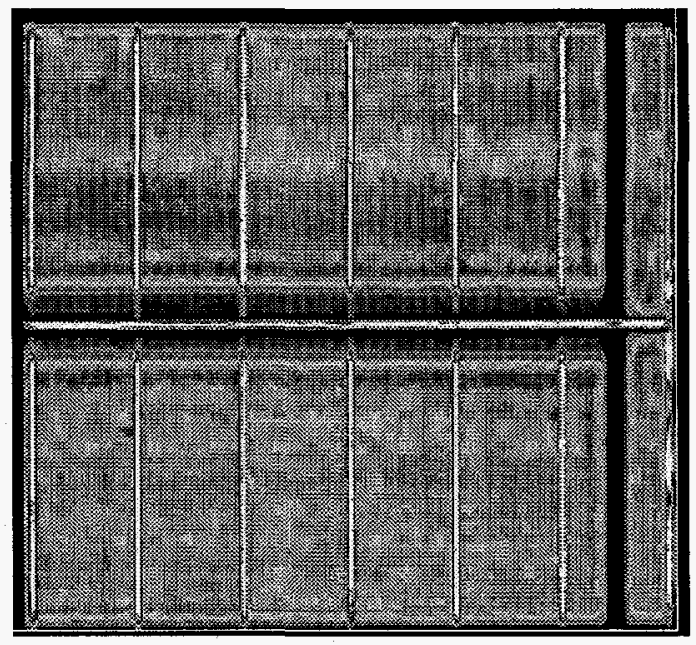

FIGURE 12. Ultrasonic image of a module scanned at a frequency of $20 \mathrm{MHz}$. Dark regions in the image indicate the presence of air voids internal to the module.

\section{Testing During Field Exposure}

As part of the MLTE baseline testing, initial outdoor performance was characterized at Sandia using a test procedure that effectively compensated for the interacting influences of irradiance, temperature, solar spectrum, and solar angle-of-incidence (16). This procedure was adapted for periodic performance testing of the MLTE modules at FSEC and SWTDI over an anticipated exposure period of at least five years. 


\section{Outdoor Performance Monitoring}

The four initial groups of modules have now been exposed at FSEC and SWTDI for approximately six months. As the exposure program continues, a series of charts for each performance parameter will be generated for each module in the program. Figure 13 illustrates an example chart generated for a silicon module that has been aging at Sandia for many years. Charts of this type will aid in the early identification of performance losses as module age. Unexposed "control" modules are also included in the MLTE program, providing another means for direct comparison after several years of exposure. Periodic reports will be provided to each module manufacturer participating in the program.

\section{Diagnosis of Degradation Mechanisms}

The synergy resulting from the collaborative approach used for the MLTE program is a significant advantage. Carefully controlled monitoring during field exposure will provide early indications of performance degradation mechanisms. The degradation mechanisms observed may differ between the hot/humid climate in Florida and the hot/dry climate in southern New Mexico. As needed, the complementary analytical and testing capabilities in the national labs and in the manufacturer's labs will be used to investigate the causes for observed degradations. The culmination of this cycle is the development of an improved manufacturing process, or material, that will eliminate the degradation mechanisms observed, taking the industry one step closer to commercial modules with lifetimes of 30 years, or more.

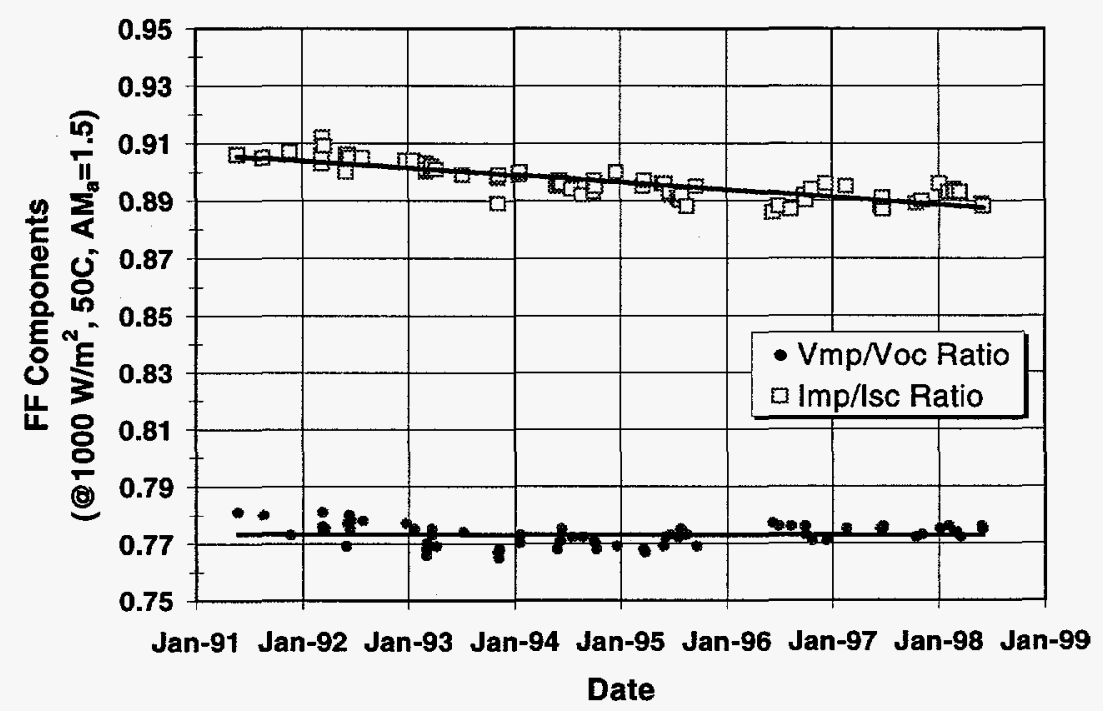

FIGURE 13. Long-term performance monitoring of a 36-cell silicon module at Sandia showing gradual decline in $I_{\mathrm{mp}} / \mathrm{I}_{\mathrm{sc}}$ ratio. Product of the two ratios is the fill factor (FF). Power from this module has declined at a rate of about $-0.4(\% / y r)$. 


\section{CONCLUSIONS}

Our investigations of both new and field-aged modules indicate that, in general, today's commercially available modules are a highly reliable product. However, using new test procedures, subtle failure mechanisms have also been identified that must be addressed in order to achieve 30-year module lifetimes. The failure mechanisms being investigated have not been adequately identified by today's accelerated qualification test procedures, indicating a need for improvement in this area. Collaborative research efforts and long-term outdoor exposure programs are in progress with several manufacturers to address known reliability issues, and to provide early identification of unexpected degradation mechanisms.

\section{ACKNOWLEDGEMENTS}

A number of people have contributed significantly to the effort documented in this paper, including Darrel Frear, Mike Hosking, John Emerson, Ginger DeMarquis, Ed Beauchamp, Mark Stavig, and Bill Boyson from Sandia; Tom McMahon at NREL: Neelkanth Dhere and colleagues at Florida Solar Energy Center; and John Wiles and colleagues at the Southwest Technology Development Institute; Jim Galica and Bill Holley at STR; and industrial collaborators at Siemens Solar, Solarex, ASE Americas, AstroPower, and United Solar Systems.

\section{REFERENCES}

1. "Photovoltaics the Power of Choice," National Photovoltaic Program Plan for 1996-2000, U.S. Department of Energy.

2. R. G. Ross, "Technology Developments Toward 30-Year-Life of Photovoltaic Modules," $17^{\text {th }}$ IEEE PVSC, 1984, pp. 464-472.

3. IEEE 1262-1995, "IEEE Recommended Practice for Qualification of Photovoltaic (PV) Modules," IEEE Standards Committee 21.

4. A. W. Czanderna and F. J. Pern, "Encapsulation of PV Modules using Ethylene Vinyl Acetate Copolymer as a Pottant: A Critical Review," Solar Energy Materials and Solar Cells, 43 (1996), pp. 101-183.

5. W. H. Holley, et al., "UV Stability and Module Testing of Non-Browning Experimental PV Encapsulants," $25^{\text {th }}$ IEEE PVSC Proceedings, 1996, pp. 1259-1262.

6. F. J. Pern and S. H. Glick, "Improved Photostability of NREL-Developed EVA Pottant Formulations for PV Module Encapsulation," 26 th IEEE PVSC Proceedings, 1997, pp. 1089-1092.

7. F. J. Pern, et al., "Spectroscopic, Scanning Laser OBIC, and I-V/QE Characterizations of Browned EVA Solar Cells," $25^{\text {th }}$ IEEE PVSC Proceedings, 1996, pp. 1255-1258.

8. N. G. Dhere, et al., "Adhesion Measurement and Analysis as a QC Tool for Module Manufacturers," NCPV Program Review Proceedings, AIP Press, Sept. 1998.

9. N. G. Dhere, et al., "Correlation Between Surface Carbon Concentration and Adhesive Strength at the Si-Cell/EVA Interface in a PV Module," $26^{\text {th }}$ IEEE PVSC Proceedings, 1997, pp. 1217-1220.

10. N. G. Dhere, K. S. Gadre, and A. M. Deshpande, "Durability of Photovoltaic Modules," $14^{\text {th }}$ European PVSEC Proceedings, 1997. 
11. D. L. King, et al., "Dark Current-Voltage Measurements on Photovoltaic Modules as a Diagnostic or Manufacturing Tool," $26^{\text {th }}$ IEEE PVSC Proceedings, 1997, pp. 1125-1128.

12. Personal communication: Jim Sweet, Sandia National Laboratories, Microelectronics \& Photonics Center, Albuquerque, NM.

13. D. R. Frear, et al., The Mechanics of Solder Alloy Interconnections, (New York: Van Nostrand Reinhold, 1994).

14. D. R. Frear, "Microstructural Evolution During the Thermomechanical Fatigue of Solder Joints," The Metal Science of Joining; eds.-Cieslak, Glicksman, Kang and Perepezko, (TMS Publications, 1992), pp. 191-200.

15. Metals Handbook, Vol. 11, "Nondestructive Inspection and Quality Control," American Society for Metals, $8^{\text {th }}$ Ed., pp. 161-198.

16. D. L. King, J. A. Kratochvil, and W. E. Boyson, "Field Experience with a New Performance Characterization Procedure for Photovoltaic Arrays," $2^{\text {nd }}$ World Conference and PVSEC Proceedings, Vienna, 1998. 